\title{
Exploring a sociocultural approach to understanding academic self- concept in twice-exceptional students
}

Geraldine Townend Griffith University g.townend@griffith.edu.au

\author{
Raymond Brown \\ Griffith University \\ ray.brown@griffith.edu.au
}

\begin{abstract}
This article explores a sociocultural approach to gaining a deeper understanding of academic self-concept by twice- exceptional students. Academic self-concept is a multidimensional, psychological construct, critical in identify formation. Twiceexceptional students are students who are gifted with a coexisting disability that affects learning. A theoretical framework is presented based on interactions within a theorised zone of proximal development using case-study methodology. Data are analysed according to the constructs of participation-in-practice, legitimateperipheral-participation, and situated learning. The discussion highlights how social practices and contexts inform the construct of academic self-concept, and how this is embedded within an individual's social interactions. Findings indicate that academic self-concept is influenced by sociocultural forces within the environment, which initially influences the construction of academic self-concept.
\end{abstract}

Key words: Vygotsky, sociocultural, participation-in-practice, legitimate-peripheralparticipation, situated learning, multiple-method research, case study, academic-selfconcept.

\section{Introduction}

Twice-exceptional students are those whose giftedness develops in relation to a learning disability (Assouline, Foley Nicpon, \& Whiteman, 2010). As a result, twice- 
exceptional students can present as a dual paradox for education systems, both in terms of having giftedness and disability simultaneously, and in terms of the lamentable lack of nurturing of a potential resource on both an individual and a national level. The paradox of two exceptionalities in schools is due primarily to behavioural issues, lack of community knowledge, and challenges with identification (Vail, 1989). Notwithstanding over twenty years of empirical research on twiceexceptional students, the influences on the academic development of twiceexceptional students, that is, perceptions about academic competence, remain virtually unexplored in a qualitative sense. As such, this paper explores the use of a Sociocultural approach to understanding the academic self-concept of twice exceptional students. Support for using a sociocultural approach to explore academic self-concept in twice-exceptional students comes indirectly from the gifted field itself, as was called for at the National Association for Gifted Children by the then President, Joyce Van Tassel-Baska, in 2006.

Academic self-concept in twice exceptional students

Academic self-concept plays a critical role in identity formation (Marsh \& Hau, 2003) and is considered to be important for academic success in school (Mendaglio, 2013). It comprises several related perceptions of self, "competence, self-worth, interest, enjoyment, and intentions, to name but a few" (Bong \& Skaalvik, 2003, 29). However, there is a paucity of research exploring the academic self-concept of twiceexceptional students (Townend \& Pendergast, 2015).

\section{Theoretical Framework}

Drawn from the work of Vygotsky (1978), the seminal works of Wertsch (1998), exploring the process of participation-in-practice, and Lave and Wenger (1991), exploring community of practice through the processes of legitimate-peripheralparticipation and situated learning, provide the basis for the development of a sociocultural approach to understanding academic self- concept in twice- exceptional students.

Participation-in-practice is the process of practising, and therefore learning, a practice. Participation in the practices of a community might also provide 'a database from which people abstract general principles and construct models of the world' (Hatano \& Wertsch, 2001. p.79). As a result, those practices that are culturally valued 
by a community are enhanced over time. If the community values the practices then they are more likely to be repeated and reinforced (Cole, 1996).

To explore academic self-concept using participation-in-practice, as posited by Hatano and Wertsch (2001), it is necessary to link social and cultural settings and practices with individual cognitive development. Interactions with others, and the contexts in which they occur, play important roles in both the learning and development of a person (Hatano and Wertsch, 2001). Of particular importance are the practices involved in the interactions (Goodnow, Miller \& Kessel, 1995). Practices such as schooling or learning to drive are organised by the culture in which the person lives and produce a significant outcome.

Legitimate-peripheral-participation is concerned with how an individual's intentions to learn are engaged, and how their academic self-concept is informed through the social, interactive process of becoming a full participant in sociocultural practice. Lave and Wenger's (1991) research into legitimate-peripheral-participation suggests that learners inevitably participate in communities of practitioners and that the mastery of knowledge and skill requires newcomers to partake fully in the sociocultural practices of the community; in other words, learning by being in the location of practice and gradually getting the 'hang of things' while being accepted by those involved. As such, legitimate-peripheral-participation provides a platform for exploring how and why twice-exceptional students, although gifted, may marginalise themselves to the periphery of the gifted population in the school institution, despite their recognised giftedness.

Situated learning pertains to social co-participation, in a specific environment, community-of-practice, or context that enables a learner to construct knowledge (Lave \& Wenger, 1991). Situated learning locates the individual's engagement with, and acceptance of, the practices within a context or community of practice, and thus how that acceptance or alignment with the practices informs the development of academic self-concept. Lave and Wenger (1991) maintain that learning is a feature of membership in a community of practice. The learning processes entail both the development of an individuals' membership in the community and the shaping of identity. Situated learning is interwoven with legitimate-peripheral-participation and 
participation-in-practice. The peripheral nature of the two latter processes ultimately become less peripheral with legitimate recognition from the community, and is often organised by the community (Gutierrez \& Rogoff, 2003).

With this understanding of theoretical constructs, a Sociocultural approach may be developed in relation to understanding the development of an individual's academic self-concept. This approach highlights those influences that are external or intermental to the individual's development, and those influences that process the internalisation, or intramental phase of development. These areas of influence may then be framed within the sociocultural notion, 'zone of proximal development' (ZPD).

Although termed a 'zone' in the literature ( Vygosky, 1978), the ZPD may be considered to be a non-physical abstract 'space' in which the inter- and intramental dimensions of development co-exist (see Figure 1). The black dots in the intermental part of Figure 1 include interactions with significant others, artefacts, social and cultural contexts and practices, legitimate-peripheral-participation, participation-inpractice, and situated learning. The white dots in the intramental plane include selfreflection, perceptions of self, and the internalised development of academic selfconcept. 


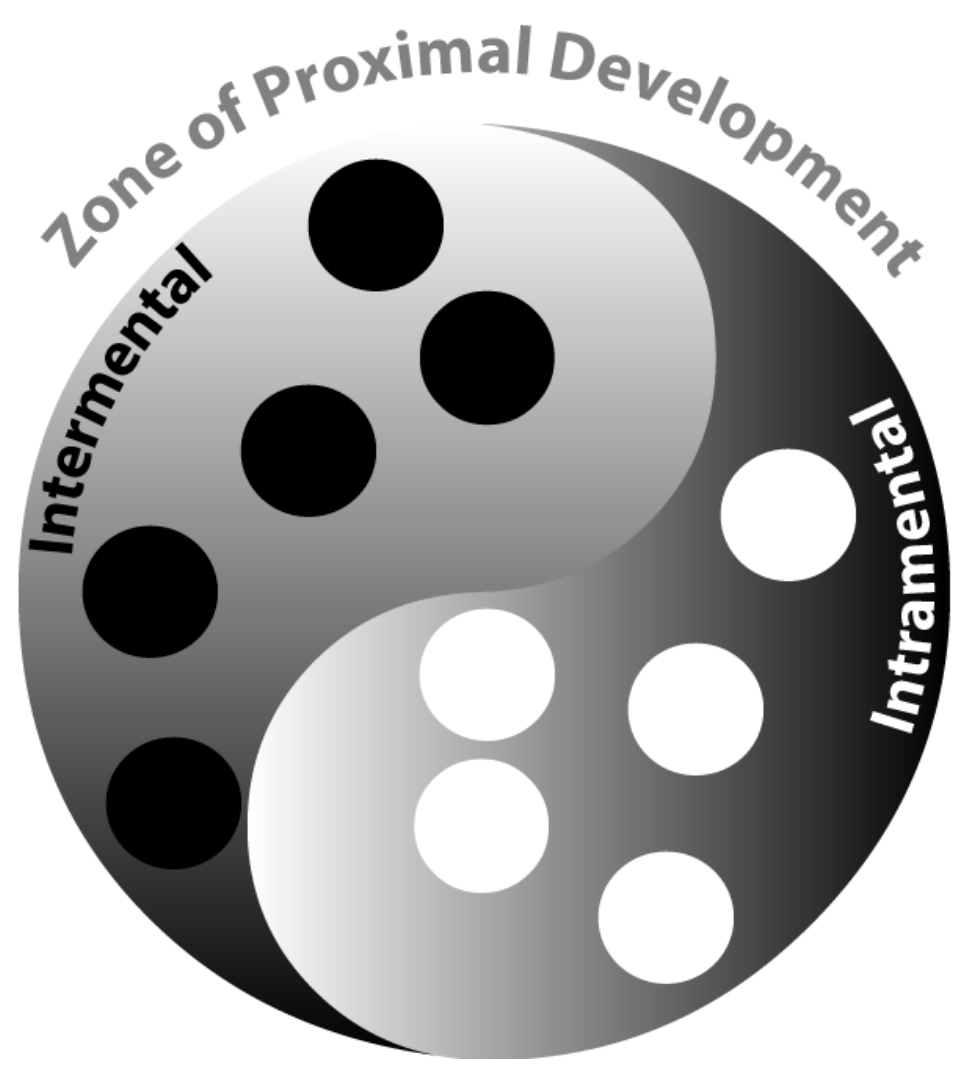

Figure 1 The fluid interchange between the inter- and intramental influences on academic self-concept.

Figure 1 illustrates a process of interchange between the intermental and intramental influences that may inform the construction of academic self-concept. Vygotsky viewed the ZPD as a way to better explain the relationship between a student's learning and cognitive development, in that learning was always posited as preceding development in the ZPD. In this sense, the ZPD provides a prospective view of cognitive development, as opposed to a retrospective view that characterises development in terms of a person's independent capabilities.

Through the lens of sociocultural theory, therefore, it can be assumed that the intermental will influence the intramental (Dole, 2001) and vice versa. The influences on academic self-concept as represented in Figure 1 can be illustrated through excerpts from a case study undertaken as part of a larger study (see Author, 2015). The case study explores a student, Aedan, and his experiences with twiceexceptionality, who was chosen for elaboration in this article as Aedan's story 
illustrates how academic self-concept changes over time within the context of schooling.

\section{Method}

In order to explore the academic self-concept of twice-exceptional students, different data collection mechanisms were utilised in a multiple case study design. The research presented here sought to provide a platform for deeper understanding of the phenomena 'academic self-concept in twice-exceptional students' through using a sociocultural-based, case-study methodology.

\section{Case study participant}

Aedan, at the time of the research, was a senior school student, aged 16, in a Year 11 class in an independent boys school located within a major Australian city. Aedan had both high psychometric test scores in one or more intelligence quotient (IQ) subscales, and a medical diagnosis of a disability that might inhibit learning. Aedan's test scores showed sub-scores above the $90^{\text {th }}$ percentile and, as such, he was considered by the school to be intellectually gifted (Gagné, 2013). He was also diagnosed in a medical specialist report as having an auditory processing disorder. Auditory processing disorder affects the process of transforming an acoustic signal at the neural level and can result in difficulties with listening, expressing, clearly using speech, reading, remembering instruction, understanding spoken messages, and maintaining focused attention (Ahmed, Musiek \& Chermak, 2008).

Aedan was engaged in the school's gifted program and had adjustments under the learning support program. The gifted program within the school involved pull-out classes for activities with other gifted students to "enhance psychosocial development and provide a support network of like-minded children" (Mrs Mender, Teacher, Personal communication, 2011). Adjustments under the learning support program did not, in Aedan's case, include specialist class withdrawal, but included the implementation of specialist medical recommendations, such as sitting front and centre of the class to eliminate background noise.

\section{Case study data collection tools}

Data were collected through the administration of standardised test instruments along with interviews of Aedan, his parents and teachers. Two standardised, psychometric test instruments were used: the Behavioural Assessment System for Children $2^{\text {nd }}$ edition (BASC-2) created by Kamphaus and Reynolds (2007), and the Piers- Harris 
Children's Self-Concept Scale $2^{\text {nd }}$ edition questionnaire (PH-2) created by Piers \& Herzberg (2002). The BASC-2 has been used by researchers in the psychological, educational and medical fields (see for example, Assouline, Foley Nipcon \& Doobay, 2009). It was designed to assist in diagnosis and classification of emotional and behavioural disorders of children at different stages of development. This instrument measures behavioural and emotional strengths and weaknesses from the perspectives of the child, their parents and their teachers. The BASC-2 indicates school problems, inattention/ hyperactivity, personal adjustment and, emotional symptoms (e.g. anxiety, attitude to school and teacher, depression, locus of control, school maladjustment, sensation-seeking, sense of inadequacy, social stress and somatization). It also indicates strengths and weaknesses on adaptive scales (e.g. interpersonal relationships, withdrawal, daily living activities, adaptability, functional communication, leadership, social skills and study skills). Insights into the influences of environment and socialization are highlighted by the BASC-2 and are particularly useful for providing insights for academic self-concept through a sociocultural lens.

The PH-2 (Piers \& Herzberg, 2002) is a self-report instrument for the assessment of self-concept in children and adolescents between the ages of seven and eighteen years of age. The PH-2 has been used extensively by researchers in the gifted and twiceexceptional fields for exploring general self-concept in students (see for example, Assouline, Foley Nipcon \& Whiteman, 2010). The PH-2 measures six subscale domains: Behavioural Adjustment (self-perceptions around problematic behaviour); Intellectual/School Status (self-perceptions in respect to intellectual and academic ability); Physical Appearance/ Attributes (self-perceptions around physical appearance, leadership and ability to express ideas); Freedom from Anxiety (items that indicate level of anxiety and dysphoric $\operatorname{mood}^{1}$ ); Popularity (self-evaluation of social functioning); and Happiness and Satisfaction (reflect feelings of happiness and satisfaction with life). Although the Intellectual/School Status domain is most closely linked to academic self-concept, some of its items also appear in other domains and can be used to validate consistency of responses and give a wider view on the psychosocial influences on academic self-concept. Scores are reported as T scores where the mean is 50 and the standard deviation is 10 . Scores of 40 or less are

\footnotetext{
${ }^{1}$ Dysphoric mood is a 'mood that taps a variety of specific emotions, including worry, nervousness, shyness, sadness, fear, and a general feeling of being left out of things' Piers \& Herzberg (2002), p.25
} 
considered "Low", and scores of 60 or more are considered "High". A report is then generated to give the overall self-concept rating with subscores related to each domain. The PH2 questionnaire was administered one-on-one in an office, which was located in the gifted classroom in the school.

\section{Case study data analysis}

All instrument data were analysed and interpreted using the recommended test parameters (Piers \& Herzberg, 2002). Interview data were analysed using thematic content analysis with both hand coding and the Leximancer software program (Smith \& Humphries, 2006). The hand coding process, devised by Strauss (1987) and Strauss and Corbin (1990) used three levels of coding that provided themes framed within a sociocultural paradigm. The hand coding was triangulated using Leximancer (Smith \& Humphries, 2006), an automated system for content analysis of text, which provided themes that, in this study, correlated with the hand coding. The interview data provided by the two analyses informed deeper insights.

The aims of the analyses were to provide insights into the perceptions of the participant, his parents and teachers, and the academic self-concept of the participant. The research design was established to provide optimal exploration of how contexts, practices and social interactions in the sociocultural paradigm inform academic selfconcept. Data sources included the participant, his parents and teachers, and their school records, along with instruments that have been used and supported within the field of gifted education. The data were explored through a multi-methods, case study design. This article focuses on Aedan, for the purpose of informing a sociocultural approach to understanding the experiences of twice-exceptional students.

\section{Case study Analysis and Discussion}

\section{Instrument data}

The instrument data revealed very low self-concept scores (PH2), and at-risk or clinical scores (BASC-2) for Aedan. The BASC-2 indicated that Aedan has a good attitude to school, has high levels of internalised problems, particularly anxiety, and perceives socialising to be achievable and successful, but difficult. He also perceives that he is hyperactive, atypical, and emotional. Aedan's perceptions are, on the whole, supported by his parents and teachers implying his high level of insight. 


\section{Interview data}

Thematic interview analysis identified emergent themes which were then compared with the literature to identify concurrent and discordant themes. The theoretical perspectives were then overlaid on the themes identified. The emergent themes from the data that related to the literature under socio-cultural theory were the big-fishlittle-pond-effect (BFLPE), significant others, environment, age, gender, academic, mastery experience, enjoyment, self-understanding, psychological centrality and selftalk. (For elaborations of the above themes see Author, 2015). However, for the purposes of this article, the big-fish-little-pond-effect may be describe as being a situation where equally able students have lower academic self-concepts in highability classes than in low-ability classes (see Marsh \& Parker, 1984). Significant others refers to important people (e.g. parents, teachers, siblings, peers) in the social sphere of a person; environment refers to the social contexts in which a person participates; academic refers to school achievement; mastery experience to the history of the attainment of knowledge and skills; and self-talk to speech spoken to oneself for self-guidance or the regulation of behaviour (see Vygotsky, Veer, \& Valsiner, 1994). Psychological centrality relates to the hierarchy of social contexts and relationships that impact a person's identity. The more central the context or relationship is to the person's identity the greater the impact on self-concept (see Rosenberg, 1979).

One emergent theme from the data that did not resonate with the literature was football. This theme was not evident in the literature as 'football' but, in analysis, was most closely linked to BFPLE as, when Aedan referred to his game, he did so most commonly by comparing his ability with his peers. Although this theme was kept for this analysis, it could be argued that the researchers could have subsumed it into BFPLE, and they chose not to, as Aedan's involvement with the game, in his daily life, was closely tied to his identity as 'a representative football player'. A sub-theme of psychological centrality is imposter syndrome (Cokley et al., 2015; Thompson, Davis \& Davidson, 1998), which is interpreted as very low self-esteem and occurs when individuals attribute their success to factors other than their own efforts, as being undeserved or accidental. Another subtheme of psychological centrality is the reflected glory effect (Cialdini et al., 1976), which has a positive influence on selfconcept. This type of effect, although recorded in studies based primarily in social 
psychology research, has also been applied to gifted education. The reflected glory can occur when high-ability students experience a boost of self-concept upon acceptance into a selective program due to their association with a successful group of people (Aberson, 1999).

\section{Instrument and interview data}

The theoretical framework represented in Figure 1 informed two analytical perspectives to analyse the interview data: 1) What are some of the social interactions that may influence the development of academic self-concept for Aedan? and 2) What are some of the social practices and contexts that may influence the development of academic self-concept for Aedan?

Social interactions: legitimate-peripheral-participation.

Instrument and interview data were analysed to inform findings of how legitimateperipheral-participation is evident for Aedan. The instrument data show that Aedan's parents consider that Aedan is caring with a sense of fun, having a friendly disposition with good social skills and that he assimilates well with his social environment. However, in contrast to this, Aedan's perceptions of himself are that, although he finds social situations relatively satisfactory, he reports that he finds interpersonal relations stressful, and that he feels 'atypical' and has a high sense of inadequacy. His teachers also report that they perceive him to be in the at-risk and clinical range ${ }^{2}$ for withdrawal and atypical behaviours. The reported atypicality and anxiety might indicate that, although Aedan is popular and considered to have good social skills, he finds he has to work hard in social situations, something that is reinforced in his interview when he stated that being with people is tiring at times: "I have learnt over time to get on and be sociable but I get pretty tired, especially if I have to force it and be sociable with people I feel inadequate around (Aedan, 2011). This reinforces the Vygotskian notion that Aeden has 'learned' to be sociable due to preceeding personal development in the ZPD which has been informed by context, and quite likely, culture (Vygotsky, 1978).

Notably, Aedan scores in the low average range in the intellectual self-concept scale of the $\mathrm{PH} 2$, and, later in interview reported that his self-concept had improved a great

\footnotetext{
${ }^{2}$ Clinical ranges denote a high level of maladaptive behaviour or absence of adaptive behaviour (Reynolds \& Kamphaus, 2004). The 'at-risk' range denotes a score that is above the 'normal' range but below the 'clinical range' (Reynolds \& Kamphaus, 2004).
} 
deal over the previous years due to recognition and support of his twice-exceptional learning needs (pull-out classes for the gifted program and scaffolding in the classroom for his disability): "I barely ever feel inadequate since I started gifted classes, and also had a reason for not having done so well, because for me it was just an easy place to connect with people" (Aedan, 2011). The low result in the intellectual self-concept domain measured on the PH2 (which is most closely related to and overlapping with academic self-concept) reinforced that Aedan feels on the periphery of his social (school) context.

Social interactions, particularly in school or within the football context, were relatively strenuous for Aedan, despite his success with them, and such interactions might exert influence upon his academic self-concept, as he found school and academic work strenuous and tiring although, more recently, successful. Examples of this include how he feels inadequate when with older peers with whom, he plays sport as he is an advanced player. He states, "I feel inadequate when I hang out with people who are a few years older than me and I feel it isn't really my place [to be with them]" (Aedan, 2011). Also, Aedan recalls when he first started the gifted classes the sense of inadequacy and social strain he felt, “...there were so many bright and intelligent kids there, I felt like I was on the lowest spectrum of intelligence.... I didn't say much so I didn't look stupid" (Aedan, 2011). With regards to legitimateperipheral-participation, the instrument data (from the $\mathrm{PH} 2$ and $\mathrm{BASC}-2$ ) indicate that Aedan, although sociable and able to conform within his context (the ZPD, Vygotsky, 1976), felt on the periphery of his social context.

For legitimate-peripheral-participation, the breakdowns of social interactions that influenced Aedan are primarily with peers and teachers. The influence of parents and siblings is comparatively low. Legitimate-peripheral-participation (Lave \& Wenger, 1991) describes how learners inevitably participate in communities of practitioners and that the mastery of knowledge and skill requires newcomers to partake fully in the sociocultural practices of the community; in other words, learning by being in the location of practice and gradually getting the 'hang of things' while being accepted by those involved. The data indicate that, for Aedan, the acquisition of skills and the sense of 'getting the hang of things' within his community of practice was particularly evident in school when he was accepted into the gifted program. Although he had a 
strong sense of inadequacy at first, he did start to recognise his strengths: "I find I have out-there ways of solving problems, I feel I am not a normal person that uses normal thinking to get the answers, and I now know that this is usual in the [gifted] class" (Aedan, 2011). He also stated: "We all bring extra things to the learning, we are all unique but this makes the group work". Also, Aedan becomes more socially confident and, although he finds socialising can be a strain, he states,

"OK - I feel that I am able to communicate with everyone in the school community easily - all of them with the same ease: whether it is my best friends or anyone. I am good at this. I now find it easy to talk to anyone no matter who they are and I get along with them all" (Aedan, 2011).

\section{Social interaction: participation-in-practice}

Practices are organised by the culture in which a developing person lives and have a relevant outcome for the individual (for example, driving or selling something). Although participation in the practice is not compulsory, contexts make the practice more accessible to young people who then might participate in them. Repeated participation enhances the performance in these practices, and thus the development of cognition, and if the culture values the practices then they are more likely to be repeated and reinforced (Cole, 1996; Scribner \& Cole, 1981).

Academic self-concept is considered domain-specific (Marsh et al., 1995) which resembles the participation-in-practice conjecture that many practices usually occur within a particular domain and the cognitive development tends to be domainspecific. However, some activities occur across many different domains (such as narratives and measurement) and the cognitive development is general and can be used in other domains. "In short, participation-in-practice is the key concept linking social and cultural setting with individual cognitive development" (Hatano \& Wertsch, 2001, p. 79).

With regards to participation-in-practice, the breakdown of social interactions that influence Aedan are primarily with teachers. The influence of peers and siblings is comparatively low, with no influences recorded for parents.

\section{Social interactions: situated learning}

The final element to be explored for social interactions is 'situated learning'. Situated learning pertains to social co-participation, in a specific environment, community-of- 
practice, or context that enables a learner to construct knowledge. Cultural practices in these communities enable learning (Lave \& Wenger, 1991). This research used three ways to explore how identities are shaped in situated learning (Wenger, 2000): engagement (doing things together, talking and producing artefacts); imagination (constructing our truths of the world: imaginative images of the world are essential to our sense-of-self and to our interpretation of our participation in the social world); and alignment (aligning our activities with community processes, such as moral codes, that can become deep aspects of our identities). Engagement and alignment activities are, for the explication of this research, foregrounded in the intermental plane and were explored in both instruments and interview transcript data where it was found that alignment was consistently associated or overlapped with either engagement or imagination.

With this understanding, the instrument and interview data were analysed to explore how 'situated learning' through the three activities of engagement, alignment and imagination impacted on Aedan's development of academic self-concept. Tables 1, 2, and 3 have examples to indicate how 'situated learning' in the form of engagement, imagination and alignment were present in the interview data. The data used for the examples have been inter-rater checked by two independent researchers with $80 \%$ agreement and $20 \%$ negotiated agreement.

Table 1 Situated learning and the interview data supporting 'engagement'

\begin{tabular}{ll}
\hline Engagement & Doing things together, talking and producing artefacts \\
\hline \%o of & $55 \%$ \\
transcript & \\
\hline Examples & But then, once I get up there and have spoken for 10 or 15 seconds \\
trom & then I feel pretty comfortable. But it's that time beforehand that I \\
& am so nervous and my thinking and everything just goes astray and \\
& $\begin{array}{l}\text { I get scared thinking like that. I would rather stand in front of the } \\
\text { firing squad than do the oral because I am so nervous. }\end{array}$ \\
& I remember thinking of trying to find excuses of why I hadn't been \\
& doing as well. But, even though I was young, I got a high getting a \\
\hline
\end{tabular}


good grade and so that is why I wanted to go further and get better grades.

Like, if you have heaps of ability but don't practise much then that probably won't make much difference but if you have a lower ability and practise heaps then you will get better results. But you have to decide - it is all your decision- to get a good grade.

Table 1 shows that $55 \%$ of Aedan's interview transcript referred to statements related to engagement. It provides three examples that highlight the diverse statements Aedan made pertaining to his engagement in school. Table 2 shows how the 'situated learning' construct of alignment presented in the interview transcript.

Table 2 Situated learning and the interview data supporting 'alignment'

\begin{tabular}{ll}
\hline Alignment & $\begin{array}{l}\text { Aligning our activities with community processes, such as moral } \\
\text { codes, that can become deep aspects of our identities }\end{array}$ \\
\hline transcript & Overlap engagement by $30 \%$ and imagination by $33 \%$ \\
\hline Examples & [On being awarded 'player of the year' in school football team:] And \\
from & afterwards everyone was saying congratulations but I felt pretty bad \\
transcript & because I didn't feel as though I deserved it. I didn't feel that I was \\
& the best player. \\
& Obviously I chose the subjects I did because I enjoy them but, \\
& because I get good grades, I feel more interested in what we're \\
& learning. Like Modern [History], even though they are not the best \\
& grades, I love learning about what happened: like at the moment it is \\
& really touchy content about apartheid - but it is really interesting... \\
& and with some bits I really gelled.
\end{tabular}

Table 2 uses two quotations as examples from each context: the first relating to alignment in imagination and the second relating to alignment in engagement. The alignment with imagination quote illustrates that Aedan has constructed identity 
aspects around 'truths of the world', concerning his comparative ability and deservedness with football, and senses that he does not deserve the credit attributed to him. As for engagement, the doing things together and producing artefacts, the notion of the co-creation [with the teacher] of making a subject 'enjoyable' was evident in the data as shown in Table 2. Table 3 shows how the situated learning construct of imagination presented in the interview transcript.

Table 3 Situated learning and interview data supporting 'imagination'

\begin{tabular}{ll}
\hline Imagination & Constructing our truths of the world - imaginative images of the \\
& world are essential to our sense-of-self and to our interpretation of \\
& our participation in the social world
\end{tabular}

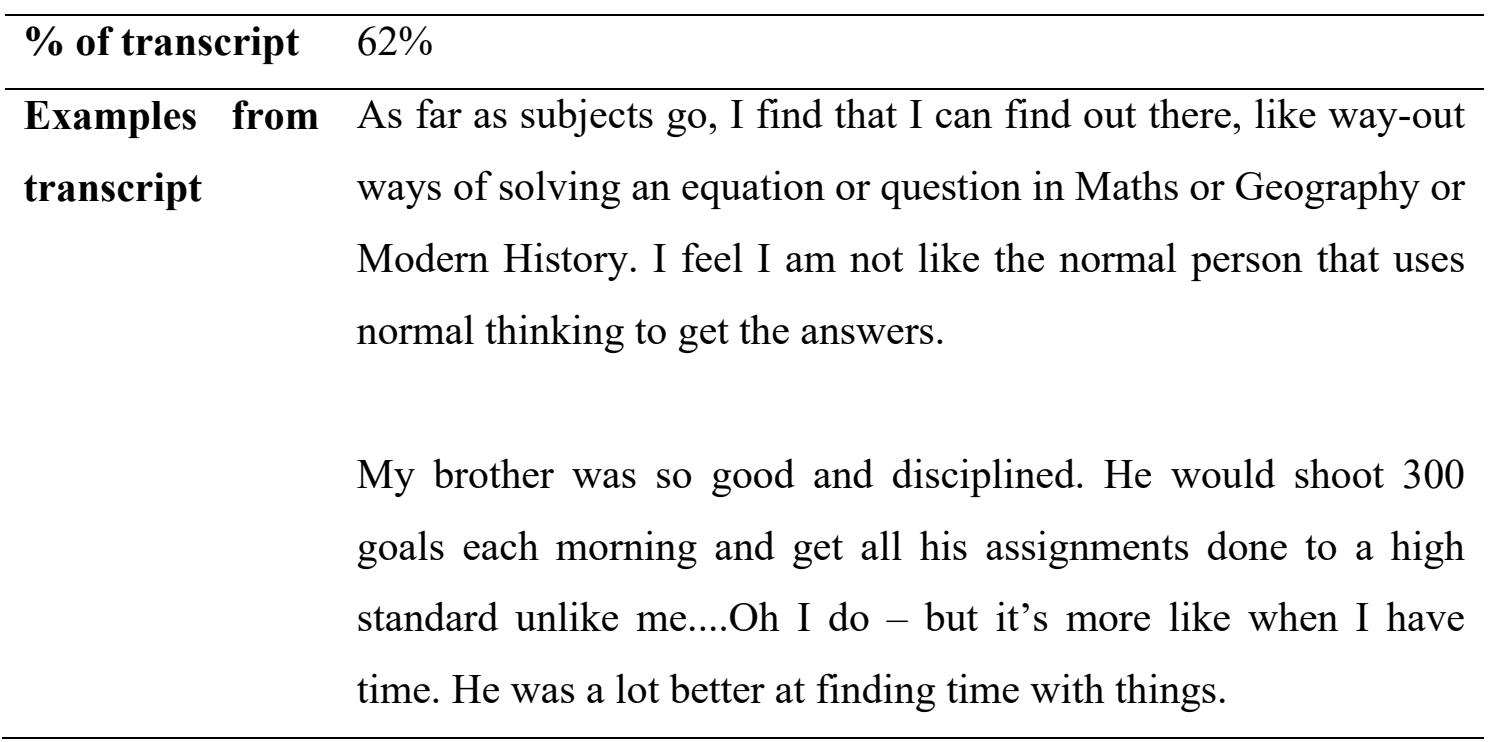

Table 3 shows two examples that highlight the diversity Aedan used pertaining to his imagination in his school community-of-practice. Aedan's construction of the 'truths' in his world, and his participation in the social world in his situated learning, was evident as he indicates how his uniqueness is a strength. However, the second quote in Table 3 indicates his sense of inadequacy around football as he compares himself to his brother, and this is a negative statement about his self-concept.

In summary, the data indicated that some social interactions do appear to influence the development of academic self-concept for Aedan. The analyses of the instruments' data show that Aedan experienced a scope of perceptions, ranging from clinical, at-risk, or normative ranges, some directly associated with academic self- 
concept and others that indirectly influence other areas of self-concept. The instruments also indicate how such perceptions align with and differ from those of his parents and teachers, , thus highlighting how Aedan's imagination, his sense-of-self in the world, is situated.

The interview data reinforced the instrument data and added layers of understanding to the perceptions that influence academic self-concept: namely BFLPE, significant others, environment, academic achievement, mastery experience, enjoyment, selfunderstanding, psychological centrality, and self-talk, all of which may be viewed through the lens of 'participation-in-practice', 'legitimate-peripheral-participation', and 'situated learning', as suggested in the preceding analyses.

\section{Relating social practices and contexts}

Aedan's interview data, together with the concurrent and discordant themes with the literature and the theoretical components of social practices and contexts as elaborated above, were integrated to give a précis of the frequency occurring in the data as seen in Table 4.

Table 4

Analysis of transcript data and frequency of occurrence*, theoretical perspectives and themes with the literature - relating to social practices and contexts.

\begin{tabular}{|c|c|c|c|c|c|c|c|c|c|c|c|c|}
\hline & $\frac{5}{9}$ & 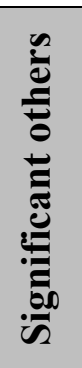 & 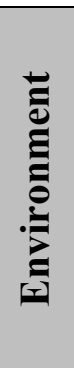 & $\sum_{4}^{\infty}$ & $\frac{\grave{0}}{0}$ & 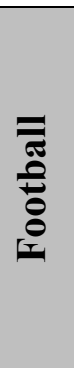 & 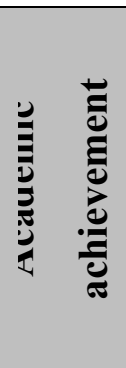 & 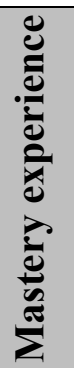 & 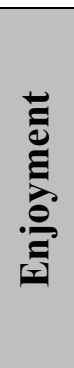 & 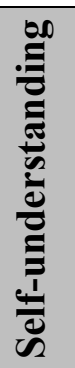 & 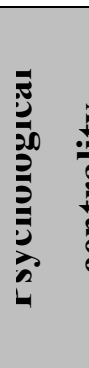 & 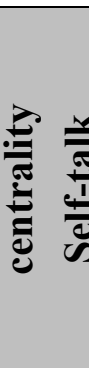 \\
\hline The context & 2 & 6 & 8 & & & 4 & 3 & 2 & 2 & 5 & 3 & 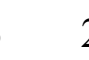 \\
\hline The practice & 6 & 10 & 14 & & & 6 & 11 & 9 & 7 & 9 & 7 & 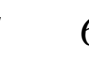 \\
\hline
\end{tabular}

*Raw occurrences of associated phrases in the interview data

For the purposes of this research, the first five themes along the top of Table 4 are foregrounded primarily in the intermental plane, for purposes of exploration. They also coincide with the theory relating to social practices and contexts. Analysis of Table 4 indicates that, for Aedan, the influences of environment, significant others, and academic achievement are predominant in his interview data, and, as such, these 
themes may have influenced the development of academic self-concept. The 'social practice' construct was more evident in the data than the 'social context'.

With regard to 'social practice' and 'social context', the relative influences of the emergent themes from the interview data, which coincide with the literature, show that social practices are about twice as evident in the data as social contexts. However, both are particularly influenced by significant others, environment and academic achievement. Additionally in Aedan's interview data, social practices, mastery experience, self-understanding, BFLPE, psychological centrality, and enjoyment are key contributors. Aedan's academic self-concept is particularly influenced both positively and negatively by social practices, and by many themes, particularly interactions with significant others, environment, academic achievement and self-understanding.

As can be seen in Table 4, significant others, self-understanding, and environment play a significant role in both social contexts and social practices. In addition, academic achievement is also a large contributor to social practices. For Aedan, when these themes were a negative influence (such as low grades for academic work) his academic self-concept was diminished, whereas, higher grades for academic work enhanced his academic self-concept. Of note is that, for both 'social contexts' and 'social practices', neither gender nor age contributed although these are considered consequential by some of the literature (such as Greenwald and Farnham, 2000; Zeidner \& Scheyler, 1999). The use of the sociocultural framework for case-study methodology has provided deeper understanding of students in an educational context.

\section{General Discussion}

The theoretical framework presented here bases social practices and contexts in the construct of situated learning (Lave \& Wenger, 1991), and allows social contexts and practices to be explored for the purpose of improving understanding about how different situations, environments, and institutions influence cultural practice and the development of academic self-concept. The case-study research reported in this article sought to explore the emergent themes evident from the data and how the data pertains to the sociocultural theoretical framework, comprising elements of situated learning, participation-in-practice and legitimate-peripheral-participation. 
For Aedan, the analysis of the social practices and contexts that influence the development of academic self-concept show varied insights. The analysis of the instrument data shows that Aedan experiences a scope of perceptions, ranging from clinical, at-risk, or normal ranges, directly or indirectly associated with academic selfconcept. The instrument data indicated that different social contexts and practices within his community-of-practice, namely whether he is at home, playing football or in the classroom or playground, do influence Aedan's sense-of-self and his academic self-concept. However, there is an overarching sense from the data that his very low academic self-concept, and low self-concept in general, both influences and is influenced by the social contexts and social practices in his experience. The interview data reinforces the instrument data and adds layers of understanding to the social contexts and practices that influence academic self-concept for Aedan.

The case-study data illustrate that the formation of academic self-concept is as a result of interactions primarily with teachers, closely followed by interactions with peers. Within the language of the sociocultural theoretical framework that guided this study, the intermental initially informs the intramental. As such, it can be stated that the sociocultural framework presented in this article provided deeper understanding of academic self-concept through its focus on the three elements of situated learning, participation-in-practice and legitimate-peripheral-participation.

In terms of theory, the research presented here supports the efficacy of using a sociocultural approach to explore academic self-concept in twice-exceptional students. Vygotsky (1978) defined sociocultural theory in terms of its roots and described learning as being embedded within the learner's interactions in their social environment. Evolving from this is the work of Wertsch (1998), exploring inter- and intra-personal processes, and Lave and Wenger (1991) exploring community of practice. Wenger's social theory of learning (2000) provides the sociocultural perspective for understanding the development of academic self-concept in twiceexceptional students. Ways of knowing (epistemology) and ways of being (ontology) are intertwined with the social dynamic of relationships. These interactions characterise learning and development, including the development of academic selfconcept, and are part of the processes of being and becoming, of shaping and 
developing identity. As illustrated in Aedan's case study, the theoretical framework proved to be a useful platform on which to investigate the complex phenomena of academic self-concept formation and provided useful scholarly research in the field of gifted education.

By integrating the works of Wertsch (1998) and Lave and Wenger (1991), a platform for exploring the processes that influence academic self-concept has been devised into a framework for research. In terms of the Zones of Proximal Development (ZPD) explored in the research presented here, the ZPD can be said to encompass and enable the interchange between the intermental plane and the intramental plane. The interchange in the ZPD was enabled through the process of mediated action in a dynamic process involving action (e.g. involvement in the gifted program), cultural tools (e.g. high grades), and contexts (e.g. experiences in the home context informing, or compared with, the school context) as mediational means (Wertsch, 1991, 1998), which facilitate and transform the processes between the two planes. As such, it can be said that the intermental, sociocultural forces, in a dynamic interaction with the intramental plane and processes, inform the development of academic self-concept in twice-exceptional students.

\section{Conclusion}

The aim of this article was to demonstrate how using sociocultural theory to frame a case-study methodology provided depth of insight and understanding when exploring the identity construct of academic self-concept in twice-exceptional students. Academic self-concept is influenced/constructed by the sociocultural forces within a twice-exceptional student's environment and can be understood through the lenses of participation-in-practice, legitimate peripheral participation, and situated learning. The authors argue that this research indicates it is the external, sociocultural forces that initially influence internal, psychological forces which influence the construction of academic self-concept. The psychological then informs how the external influences are perceived, which then influence the psychological and so on.

There are three implications for classroom practice that arise from this research. Firstly, teacher education programs need to be alert to unidentified students presenting as twice-exceptional. Secondly, tiered counselling needs to be provided to support the psychosocial needs of twice-exceptional students. Thirdly, environmental 
and programming adjustments need to be made available to twice-exceptional students, adjustments that recognise that they are gifted first, but may require additional support for learning disabilities. It is the authors' contention that the sociocultural theoretical framework elaborated in this article can inform and support the implementation of the above.

The research presented here was limited to the explication of one case-study and therefore did not set out to enable generalisations to be made to the wider community of twice-exceptional students but, rather, to provide deeper insights into this littleresearched phenomenon. However it does point to the need for future research, based on a sociocultural approach to learning and development, to investigate and make explicit accessible methods that enhance the identification of twice-exceptional students in schools; to explore how to systemise the counselling needs of twiceexceptional students, including how to effectively address psychosocial needs of twice-exceptional students, and to classify the environmental and programming adjustments, employing optimal pedagogical approaches, to inform and enable practice and policy.

\section{References}

Aberson, C. L. (1999). Low self-esteem and ingroup bias. Personality and Social Psychological Review. 4(2), 157-173.

Ahmed, N., F, E., Musiek, G. D., \& Chermak. (2008). HANDBOOK OF (CENTRAL) AUDITORY PROCESSING DISORDER. The Journal of Laryngology and Otology, 122(7), 765. doi:10.1017/S0022215107001430

Assouline, S. G., Foley Nicpon, M., \& Whiteman, C. (2010). Cognitive and Psychosocial charactersitics of gifted students with written language disability. Gifted Child Quarterly 20(10), 14. doi:10.1177/0016986209355974

Assouline, S. G., Foley Nipcon, M., \& Doobay, A. (2009). Profoundly gifted girls and autism spectrum disorder: A psychometric case study comparison. Gifted Child Quarterly, 20(10).

Bong, M., \& Skaalvik, E. M. (2003). Academic self-concept and self-efficacy: How different are they really? Educational Psychology Review, 15(1), 1-40.

Cialdini, R. B., Borden, R. J., Thorne, A., Walker, M. R., Freeman, S., \& Sloan, L. R. (1976). Basking in reflected glory: Three (football) field studies. Journal of Personality and Social Psychology, 34(3), 366.

Cokley, K., Awad, G., Smith, L., Jackson, S., Awosogba, O., Hurst, A., . . Roberts, D. (2015). The Roles of Gender Stigma Consciousness, Impostor Phenomenon and Academic Self-Concept in the Academic Outcomes of Women and Men. Sex Roles, 73(9), 414426. doi:10.1007/s11199-015-0516-7

Cole, M. (1996). Cultural psychology: A once and future discipline. Cambridge, MA: Harvard University Press. 
Dole, S. (2001). Reconciling contradictions: Identity formation in individuals with giftedness and learning disabilities. Roeper Review. 23(1), 28-37.

Gagné, F. (2013). The DMGT: Changes Within, Beneath, and Beyond. Talent Development and Excellence, 5(1), 5-19.

Goodnow, J. J., Miller, P. J., \& Kessel, F. E. (1995). Cultural practices as contexts for development. Jossey-Bass.

Greenwald, A. G., \& Farnham, S. D. (2000). Using the implicit association test to measure self-esteem and self-concept. Journal of Personality and Social Psychology, 79(6), 1022-1038. doi:10.1037//0022-3514.79.6.1022

Gutiérrez, K. D., \& Rogoff, B. (2003). Cultural Ways of Learning: Individual Traits or Repertoires of Practice. Educational Researcher, 32(5), 19-25. doi:10.3102/0013189X032005019

Hatano, G., \& Wertsch, J. V. (2001). Sociocultural approaches to cognitive development. Human Development, 44(2-3), 98-102.

Reynolds, C. R., \& Kamphaus, R. W. (2007). Behaviour assessment system for children second edition. In S. R. Smith \& L. Handler (Eds.), The clinical assessment of children and adolescents: a practitioner's handbook (pp. 31-325). New Jersey: Lawrence Erlbourn Associates.

Lave, J., \& Wenger, E. (1991). Situated Learning: Legitimate peripheral participation (R. P. J. S. Brown Ed.). Sydney: Cambridge University Press.

Marsh, H. W., Chessor, D., Craven, R., \& Roche, L. (1995). The effects of gifted and talented programs on academic self-concept: The big fish strikes again. American Educational Research Journal, 32(2), 285-319.

Marsh, H. W., \& Hau, K. T. (2003). Big-fish-little-pond effect on academic self-concept: A cross- cultural (26 country) test of the negative effects of academically selective schools. The Amercian Psychologist, 58(5), 364-376.

Marsh, H. W., \& Parker, J. W. (1984). Determinants of student self-concept: Is it better to be a relatively large fish in a small pond even if you don't learn to swim as well? Journal of Personality and Social Psychology, 47(1), 213-231. doi:10.1037/00223514.47.1.213

Mendaglio, S. (2013). Gifted students transition to university. Gifted Education International, 29(3), 3-12.

Piers, E. V., \& Herzberg, D. S. (2002). Piers-Harris Children's Self-Concept Scale (2nd ed.). Los Angeles, CA: Western Psychological Services.

Rosenberg, M. (1979). Conceiving the self. New York: Basic.

Scribner, S., \& Cole, M. (1981). The psychology of literacy. Cambridge, MA: Havard University Press

Smith, A. E., \& Humphreys, M. S. (2006). Evaluation of unsupervised semantic mapping of natural language with Leximancer concept mapping. Behavior Research Methods, 38(2), 262-279. doi:10.3758/BF03192778

Strauss, A. L. (1987). Qualitative analysis for social scientists, New York, NY: Cambridge University Press

Strauss, A. L., \& Corbin, J. M. (1990). Basics of qualitiatve research: Grounded theory, procedures, and techniques. Thousand Oaks, CA: Sage

Thompson, T., Davis, H., \& Davidson, J. (1998). Attributional and affective responses of impostors to academic success and failure outcomes. Personality and Individual Differences, 25(2), 381-396. doi:10.1016/S0191-8869(98)00065-8

Author (2015

Townend, G., \& Pendergast, D. (2015). Student voice: What can we learn from twiceexceptional students about the teacher's role in enhancing or inhibiting academic self concept. Australasian Journal of Gifted Education, 24(1), 37-51. 
Vail, P. L. (1989). Smart kids with school problems: things to know and ways to help. New York: Plume.

Vygotsky, L.S. (1978). Mind in society. The development of higher psychological processes. Cambridge, MA: Harvard University Press

Vygotskiĭ, L. S., Veer, R. v. d., \& Valsiner, J. (1994). The Vygotsky reader. Oxford, UK: Blackwell.

Wenger, E. C. (2000). Communities of practice: The organizational frontier (Vol. 78, pp. 139139). Boston: Havard Business School Publishing Corporation.

Wertsch, J. V. (1991). Voices of the mind: A sociocultural approach to mediated action. Cambridge, MA: Harvard University Press, 1991.

Wertsch, J. V. (1998). Mind as action. Oxford; New York: Oxford University Press

Zeidner, M. \& Schleyer, E. J. (1999). The big-fish-little-pond effect for academic self-concept, test anxiety, and school grades in gifted children. Contemporary Rducational Psychology, 24(4), 305. 